\title{
ИНТЕРСУБЪЕКТИВНОСТЬ В АСИММЕТРИЧНОМ ВЗАИМОДЕЙСТВИИ
}

Традиционной точкой отсчета для исследований в области этнометодологии и конверсационного анализа (EMCA) является компетентный член общества, демонстрирующий в своих действиях, как были поняты предшествующие действия. Публичная видимость взаимных интерпретаций обеспечивает взаимопонимание, поскольку ошибки сразу становятся заметными. Это условие не всегда выполняется в асимметричном взаимодействии, у участников которого способы восприятия окружающего мира отличаются. Ярким примером являются люди с инвалидностью, которая «закрывает» для них одни регистры взаимодействия и открывает другие. В статье обсуждаются условия достижения взаимопонимания в таком случае. Рассматривается конверс-аналитическая концептуализация взаимопонимания, или интерсубъективности, как локального достижения, обеспечиваемого фундаментальными структурами взаимодействия, такими как система чередования говорящих в разговоре. Такая концептуализация не дает ответа на вопрос, что делает возможным взаимопонимание, когда у участников неравный доступ к этим структурам. В статье аргументируется, что эффективность структур взаимодействия в обеспечении взаимопонимания сама основана на приобретаемой способности ориентироваться на другого. Автор предлагает называть эту способность интерсубъективностью и отличать ее от взаимопонимания внутри ситуации. Также рассматриваются телесность и речь в качестве фундаментальных оснований интерсубъективности. Демонстрируется, что замена одного ресурса другим (например, использование синтезатора речи) успешна только если участники телесно ориентированы друг на друга. Организация разговора, направленная на обеспечение взаимопонимания, в асимметричном взаимодействии

Мария Александровна Ерофеева- к.социол.н., н.с., Центр социологических исследований РАНХиГС; ст.н.с., Международный центр современной социологической теории, Московская высшая школа социальных и экономических наук, Москва, Россия. Электронная почта: erofeeva-ma@ranepa.ru 
может препятствовать его достижению из-за того, что привычные структуры взаимодействия продолжают использоваться в фоновом режиме. Автор иллюстрирует эти тезисы на основании примеров современных эмпирических исследований из области ЕМСА.

Ключевые слова: этнометодология и конверсационный анализ, атипичное взаимодействие, мультимодальность, семиотические поля, интеркорпоральность

DOI: 10.17323/727-0634-2021-19-4-635-650

Точкой отсчета для любого взаимодействия является наличие базового уровня понимания между взаимодействующими, который может быть концептуализирован как общее внимание или вовлеченность, принятие роли другого, доверие или разделяемые ожидания. Мы будем пользоваться понятием интерсубъективности. Независимо от конкретной концептуализации (Sidnell 2014), интерсубъективность основана на допущении относительной симметрии взаимодействующих. Альфред Шюц (2004: 15) емко сформулировал эту идею во «всеобщем тезисе взаимности перспектив»: мы отбрасываем различия в индивидуальных перспективах восприятия, потому что предполагаем, что: (а) мы видим мир так же, как и любой другой, окажись он на нашем месте; (б) биографически мотивированная заинтересованность в объектах общего мира не влияет на их одинаковое восприятие.

Идеализации взаимности перспектив выполняются по отношению к компетентному члену общества, «здоровому, взрослому и бодрствующему человеку» (там же: 78). Если же разрыв между индивидуальными перспективами велик, например, по причине различий в аппарате восприятия (слепота, глухота), взаимодействующие не могут полагаться на допущение симметрии их позиций. Такое взаимодействие можно охарактеризовать как асимметричное. Важно отметить, что это относительная категория, зависящая от статусов участников друг относительно друга, от специфики доступных им интеракционных ресурсов. Ее характерной чертой является «раздробленность» (fracture) экологии взаимодействия, т.е. ограниченный доступ к воспринимаемым средам друг друга (Luff et al. 2003). Яркий пример асимметрии перспектив- наличие сенсорной инвалидности. Асимметричное взаимодействие проблематично, потому что, даже если стороны понимают, что видят мир по-разному, у них нет под рукой других идеализаций. Так, согласно Эрвину Гоффману (Goffman 1963), «нормальные» склонны взаимодействовать со стигматизированными индивидами как ни в чем не бывало, что может выглядеть со стороны последних как нечувствительность.

Интерсубъективность в асимметричном взаимодействии также проблематизируется; достижение взаимопонимания становится сложной практической проблемой, требующей значительных усилий. Для многих форм атипичной коммуникации характерны задержки продвижения разговора (delays in progressivity)- минимизации препятствий для его течения (Wilkinson 
2019). Например, ответ на вопрос «Что ты будешь на завтрак?», который обычно дается моментально, у человека с афазией (расстройством речи) занимает полминуты (Goodwin 1995). Можно возразить, что любое взаимопонимание представляет собой практическую проблему, поскольку способы восприятия мира, какими бы они ни были близкими, не идентичны и должны постоянно согласовываться. В этом смысле нет никакой сущностной разницы между здоровыми и взрослыми людьми и теми, кто не попадает в эту категорию (Goodwin 2018: 88-90). В любом случае взаимопонимание будет практическим достижением участников взаимодействия. Это позиция этнометодологии и конверсационного анализа $(E M C A)$.

Исследования в $E M C A$ основываются на идее, что смысл действий становится доступным другим в самом их осуществлении (нам не нужно говорить «я задаю вопрос», чтобы задать вопрос, т. к. само действие вопрошания одновременно передает информацию о том, что задается вопрос). Действия производятся как «естественно анализируемые» (Корбут 2015), т.е. открытые для интерпретации. Корректность или ошибочность последней, в свою очередь, обнаруживает себя в следующем действии. Так, например, вопрос в ответ на вопрос может свидетельствовать о том, что адресат не понял, о чем его спрашивают. Своими действиями люди демонстрируют, что для них релевантно. По реакции на отсутствие ответа на вопрос можно понять, насколько данный ответ является ожидаемым.

Проблема взаимодействия нормотипических людей с людьми с инвалидностью (ЛсИ) заключается в различии доступных им интеракционных каналов (речь, зрение, слух, движения тела). ЛсИ, вследствие своих особенностей, часто показывают, что для них релевантно, непривычным, а значит затрудненным для считывания способом. Это означает, что естественный анализ их действий требует дополнительных усилий, по крайней мере если условно здоровые люди не имеют опыта подобных взаимодействий. Наглядный пример: слепые младенцы улыбаются родителям гораздо реже зрячих, реагирующих на знакомые лица. Мать слепого ребенка может неверно интерпретировать отсутствие улыбки как отсутствие интереса или эмоциональной реакции, в то время как для младенца выражение лица просто не является доминирующим экспрессивным каналом (Valente et al. 2018). Таким образом, в некоторых случаях смысл действий ЛсИ оказывается интерсубъективно недоступен, что превращает в практическую проблему не только взаимопонимание, но и сами условия его достижения. Чтобы ответить на вопрос, как возможно взаимопонимание в асимметричном взаимодействии, обратимся к концептуализации интерсубъективности в $E M C A$.

\section{Интерсубъективность как достижение}

В EMCA интерсубъективность рассматривается как практическое достижение. Эта идея присутствует еще в феноменологии Шюца: у людей 
нет никаких внешних гарантов взаимопонимания, кроме осуществляемой ими деятельности по поддержанию идеализаций взаимности перспектив (Heritage 1984:56). Интерсубъективность, как ее понимает Шюц, зиждется на разделяемом знании и поэтому центрирована на восприятии. Коммуникация сводится к взаимной реконструкции внутренних переживаний собеседников. В противоположность этому, Гарольд Гарфинкель размещает взаимопонимание в самих действиях; мы не просто воссоздаем в своем сознании картину мира другого, а совместно участвуем в производстве интерсубъективности шаг за шагом. Отличие $E M C A$ от феноменологии в том, что понимание меняется в ситуации как реакция на действие участника.

В результате в $E M C A$ происходит «локализация» интерсубъективности. Взаимопонимание достигается здесь-и-сейчас-в-ситуации. Локализация приводит к тому, что интерсубъективность, с одной стороны, становится «эфемерной», т.к. каждое действие может обнажить отсутствие понимания. Дирк фон Лен пишет о посетителях музеев:

Интерсубъективность, достигаемая в эти моменты, носит эфемерный характер, потому что она исчезает снова, как только начинается следующее действие. В следующем действии и реакции [на него] ... участники подтверждают, что они по-прежнему рассматривают произведение искусства согласованно (vom Lehn 2018: 118).

С другой стороны, интерсубъективность достигается все время, т.е. постоянно и каждый раз. Она, в сущности, не может быть потеряна внутри взаимодействия, т. к. каждое действие открыто для интерпретации, и потеря взаимопонимания будет замечена сразу же.

Если все, происходящее во взаимодействии, является локальным достижением, интерсубъективность может быть приравнена к пониманию. Эта тенденция наблюдаема во многих текстах $E M C A$. При этом понятие интерсубъективности введено Шюцем для обозначения фундаментальных условий взаимопонимания. Эммануил Щеглофф приписывал ему такую же функцию«основания и ресурсов для понимания» (Schegloff 1992: 1299). Чтобы рассматривать интерсубъективность как достигаемое условие достижения понимания, необходимо обнаружить ее собственные основания.

\section{Инфраструктура взаимодействия}

Ответ на вопрос об основаниях интерсубъективности появляется уже в ранних работах по конверс-анализу (Schegloff 1992; Сакс и др. 2015). Взаимопонимание обеспечивается структурами взаимодействия- системой очередности (turn-taking), последовательностной организации действий (sequencing), предпочтения (preference) и исправления/починки/поправки (repair). Названные системы основаны на характеристиках самих действий, которые являются подотчетными (accountable) (Garfinkel 1967), открытыми 
для интерпретации, и связанными отношениями «условной релевантности»-conditional relevance (Sidnell 2014). Иными словами, они обуславливают друг друга через демонстрацию в самих действиях того, на что ориентируются участники. Например, при использовании последовательности «вопрос-ответ» задающий вопрос ждет ответа, а отвечающий осознает его условную обязательность.

Структуры взаимодействия обладают принудительной силой: «Организация очередности в разговоре принуждает его участников демонстрировать друг другу в чередных репликах свое понимание других чередных реплик» (Сакс и др. 2015: 189). Хотя понимание не гарантировано (можно что-то не услышать, не обратить внимание, не придать значение), люди довольно хорошо защищены от непонимания структурами взаимодействия. Щеглофф (Schegloff 1992) эксплицитно называет механизм исправления защитой интерсубъективности в разговоре. Он заключается в том, что говорящий может либо сам исправиться, если он совершил ошибку, например переформулировать высказывание, либо исправление может исходить от реципиента, например в форме уточняющего вопроса. При этом исправление может инициироваться не только во второй позиции, непосредственно следующей за источником затруднения (trouble source), но и в третьей, когда говорящий осознает, что его поняли неправильно, и даже в четвертой, когда реципиент замечает, что его ответ был основан на неверном понимании изначальной реплики.

Этот ответ стирает различение интерсубъективности и взаимопонимания. Сама структурная организация взаимодействия обеспечивает понимание между людьми: «[C] помощью этой организации систематически поддерживается контекст публично демонстрируемых и постоянно обновляемых интерсубъективных пониманий» (Heritage 1984:259). Структуры взаимодействия обладают статусом базового уровня социального действияего инфраструктуры (Schegloff 1992). Социальный порядок неустойчив, поскольку любое действие может стать источником непонимания. При этом любое непонимание может быть проблематизировано и исправлено, что делает инфраструктуру взаимодействия локусом порядка (Ibid: 1338).

Система исправления в разговоре эффективна, потому что любое высказывание может быть подвергнуто исправлению, включая исправляющие высказывания. Как тогда возникает непонимание? Щеглофф называет несколько возможностей. Во-первых, непонимание может просто остаться незамеченным. Во-вторых, один или оба участника по разным причинам могут решить не исправлять некорректную интерпретацию (если они не заинтересованы, считают проблему незначимой, восприняли некорректное высказывание как шутку). Эти возможности объединяет то, что в обоих случаях один или оба говорящих либо не замечают, что они перестали понимать друг друга, либо игнорируют этот факт. В остальных случаях у участников есть понимание (не)понимания. Здесь мы предлагаем 
провести различение и считать интерсубъективностью не эфемерное мерцание взаимопонимания внутри ситуации, а способность участников ориентироваться на непонимание на практическом уровне. Музейный гид, разумеется, осознает, что незрячий человек не видит тактильную версию картины, но все равно использует жест для указания (vom Lehn 2010). В таком случае можно говорить об отсутствии интерсубъективности.

Как способность интерсубъективность выходит за пределы ситуации. Она связана с умением действовать в рамках существующей инфраструктуры, которое не появляется сразу: «Приобретение интерактивной компетентности... составляет основу детской социализации» (Heritage 1984:239). В асимметричном взаимодействии интерсубъективность проблематична, так как некоторые ЛсИ могут не иметь равного доступа к универсальной инфраструктуре взаимодействия (Kendrick et al. 2020). Она достигается не в рамках ситуации, а в процессе длительной работы. В своем исследовании жизненного мира слепоглухих детей Дэвид Гуд (Goode 1994) подробно описывает достижение интерсубъективности с девятилетней Кристиной, не имеющей языка и с пяти лет находящейся в интернате для детей с интеллектуальной инвалидностью. В течение нескольких месяцев Гуд проводил интенсивное наблюдение за девочкой, непрерывно находясь с ней рядом, а также осуществляя практики, направленные на подстройку собственного аппарата восприятия, такие как завязывание глаз и затыкание ушей. В результате они выработали общую «лексику тела»- совокупность поз и движений, сигнализирующих другому о намерениях и переживаемых эмоциях.

\section{В поисках других оснований}

Разговор- только одна из инфраструктур взаимодействия. Щеглофф прямо указывает на то, что неречевые практики содержат в себе другие способы ее поддержания (Schegloff 1992: 1341). Для некоторых ЛсИ речь не обязательно является надежным ресурсом, поэтому встает вопрос, на чем еще может быть основана интерсубъективность. В организации взаимодействия помимо речи задействованы такие телесные (embodied) модальности, как жесты, направление взгляда, движение тела, расположение в пространстве и т.д. (Mondada 2016, 2019). Они представляют собой семиотические поляупорядоченные совокупности знаков, воплощенные в определенной среде (medium) (Goodwin 2018: 169-170). Например, семантическое содержание речи и просодия представляют собой разные поля. Каждое из них организует взаимодействие особым образом. Речь предполагает соблюдение очередности, в то время как жесты могут производиться вместе с речью. Мультимодальность, то есть рассмотрение того, как люди одновременно используют различные интерактивные ресурсы, привносит в $C A$ идею о том, что взаимопонимание возникает на пересечении множества семиотических полей. 
Хотя комбинация различных семиотических ресурсов осуществляется самими взаимодействующими, она не произвольна, поскольку, во-первых, у них может быть ограниченный доступ к определенным инфраструктурам взаимодействия (например, человек с некоторыми формами афазии не может использовать символы языка), во-вторых, они не могут изменить структурирующий принцип того или иного поля (если мы не будем грамматически корректно выстраивать фразу, нас могут не понять), наконец, им необходимо учитывать действия других участников. Соответственно, демонстрация релевантности и основанное на ней взаимопонимание ограничены структурой самих семиотических полей.

Из сказанного выше можно предположить, что асимметричное взаимодействие характеризуется только различиями в аппарате восприятия. Однако понятие семиотического поля включает в том числе идею курса действий, то есть контекста деятельности, в рамках которого разворачивается то или иное действие. В конверс-анализе контекст фиксируется в понятии релевантного следующего: люди доверяют друг другу в способности выстраивать следующее действие таким образом, что оно не только будет демонстрировать интерпретацию предыдущего, но и встраиваться в выполнение совместной деятельности, будь то разговор, проведение хирургической операции или школьный урок. Интерсубъективность, как мы ее определили, связана с освоением структуры семиотических полей, в том числе курса действий. Значит, взаимодействие с некоторыми ЛсИ характеризуется не только различиями в аппарате восприятия, но и потенциально разным статусом участия в совместной деятельности. Например, Гоффман описывает одну из стратегий обращения с людьми, обладающими стигматизированным качеством, заключающуюся в их полном игнорировании (Goffman 1963: 18). В таком случае они не рассматриваются как участники, способные произвести следующее релевантное действие.

Тем не менее исследования $E M C A$ показывают, что даже в условиях значительной асимметрии можно систематически достигать взаимопонимания (Goode 1994; Goodwin 1995). Обычно это связано с длительным процессом сонастройки взаимодействующих друг на друга. Теперь можно уточнить наше определение: интерсубъективность является сформированной интерактивной компетентностью, которая складывается в процессе научения использованию доступных ресурсов. При этом она может различаться по курсу действия. Быть компетентным спикером- не то же самое, что быть компетентным археологом (Goodwin 2018). Разница между этими двумя компетентностями не в используемых ресурсах, а в том, какое действие будет рассматриваться как следующее релевантное в рамках совместной деятельности.

Несмотря на то, что сама интерсубъективность не локальна, процесс ее формирования разворачивается в ситуациях, которые предоставляют доступные ресурсы для взаимодействия. В случае асимметрии доступ 
к ресурсам различается, поэтому и локальное взаимопонимание и интерсубъективность могут быть проблематичны. Соответственно, должны существовать более фундаментальные основания интерсубъективности, чем семиотические поля. В работах $E M C A$ можно выделить три таких основания: тело, речь и объекты.

\section{Интерсубъективность и взаимопонимание в асимметричном взаимодействии}

Начиная с 2000-х гг. в конверс-анализе происходит «телесный поворот» (Nevile 2015), в центре которого- одновременное рассмотрение множества модальностей взаимодействия. Важным тезисом исследований мультимодальности является отсутствие иерархии ресурсов (Mondada 2016: 338). Такой взгляд влечет за собой идею ресурсной компенсации. Когда определенная модальность недоступна, можно обратиться к другим для реализации той же самой цели. Например, незрячий человек использует белую трость для навигации и сообщения зрячим людям о статусе своего зрения (Due, Lange 2018a). На этой же логике основана идея, что можно компенсировать отсутствие речи у людей с анартрией (неспособностью производить речь) с помощью синтезатора речи (Auer, Hörmeyer 2017).

Однако семиотические поля структурированы, что делает их более подходящими для определенных действий и менее подходящими для других. Питер Ауэр и Ина Хёрмейер (Auer, Hörmeyer 2017) в исследовании взаимодействия людей с церебральным параличом с их близким окружением (родители, друзья, ассистенты) обнаружили, что они стремятся использовать синтезатор речи как можно реже. Поскольку парализованным людям трудно контролировать свое тело, печать на компьютере занимает много времени и не может угнаться за темпом обычного разговора. Тем не менее использование синтезатора было успешным в случае телесной синхронизации участников. В одном из анализируемых кейсов друзья и мама ребенка с параличом смотрят в его экран, пока он печатает, и на основании появляющихся букв строят предположения о релевантных следующих. В этом примере тело как основание различных семиотических полей необходимо для удачного использования объекта-синтезатора речи.

\section{Интеркорпоральность}

Свежие тренды в области конверс-анализа связаны с более глубоким пониманием роли тела в социальном взаимодействии. Мондада (2019) обращает внимание на чувствующие (в противоположность воспринимающим) тела, разрабатывая концепт мультисенсориальности, и предлагает программу изучения невизуальных модальностей, таких как осязание, обоняние, вкус. В ее проекте биологические аспекты человеческой социальности 
выносятся в определенную сферу практик, например дегустационных. Концепт интеркорпоральности (Meyer et al. 2017), в свою очередь, приписывает телесным практикам роль базового уровня взаимопонимания, существующего до приобретения языка и культуры.

Названные тенденции объединяет внимание к телу как источнику ощущений от внешнего мира. Тем не менее устроены они по-разному. Трактовка Мондады расширяет предмет мультимодального анализа, включая в него чувственное восприятие: взаимодействующие используют «мультимодальные ресурсы не только для коммуникации или обеспечения подотчетности взаимодействий, но также для выражения, проявления и демонстрации своего чувственного доступа к миру» (Mondada 2019: 50). В этой интерпретации сенсориальные практики не выходят за границы ситуаций и сами становятся предметом анализа. В трактовке Мейера и коллег (Meyer et al. 2017) чувственное восприятие лежит в основе любых практик. Оно одновременно локализовано в ситуациях и выходит за их пределы благодаря аккумуляции- накоплению телесных навыков и способов воспринимать мир и действовать в нем. Археологи из исследования Чарльза Гудвина (Goodwin 2018) могут вместе классифицировать цвет почвы благодаря тому, что они умеют пользоваться таблицей цветов и шпателем. Что важно в контексте нашего обсуждения, понятие интеркорпоральности лежит в основе любых практик научения, а значит позволяет объяснить достижение интерсубъективности.

Взаимопонимание обеспечивается инфраструктурами взаимодействия, такими как очередность или исправление, а участники должны уметь ими пользоваться, т.е. находиться в интерсубъективном отношении. В условиях асимметрии из-за неравного доступа к семиотическим полям частой будет конфигурация «компетентный- не компетентный». Это не означает, что взаимопонимание вообще невозможно, просто оно не обеспечивается используемыми структурами взаимодействия. Некоторые ЛсИ в силу своих особенностей восприятия не могут развить требуемую интерактивную компетентность, например, вдруг заговорить. Зато участники асимметричного взаимодействия могут попытаться подстроиться под необычные условия. Поскольку телесность является всеобщим знаменателем, она выступает опорой для формирования интерсубъективности, когда участники не могут полагаться на общность ресурсного репертуара. Даже в случае крайней асимметрии, когда Гуд (Goode 1994) пытался проникнуть в жизненный мир слепоглухой Кристины, взаимопонимание стало возможным, когда этнометодолог освоил альтернативную инфраструктуру взаимодействия, всецело основанную на телесной синхронизации. Аналогично, работа по избеганию столкновений со слепым в публичном пространстве осуществляется в основном зрячими (Due, Lange 2018b).

Объяснить главенствующую позицию телесности можно, если вновь обратиться к понятию курса действий. Действия людей связываются 
в цепочки отношениями релевантности: каждое следующее выражает интерпретацию предыдущего в рамках определенной деятельности. Через телесную ориентацию мы демонстрируем другим, насколько рассматриваем их как участников, способных совершить следующее релевантное действие в рамках последовательности. Показательным примером является следующее взаимодействие слепого с собакой-поводырем. Брайан Дью и Саймон Ланге подробно рассматривают кейс, когда собака отклоняется от привычного маршрута. Ее хозяин пытается осуществить исправление с помощью серии высказываний (вопрос «это правильно?» и несколько версий команды), однако поводырь своим движением «настаивает на «правильном» направлении» (Due, Lange 2018a: 302). Несмотря на то, что исправление не возымело никакого эффекта, хозяин просто подчиняется своей собаке. Охранительная структура взаимодействия здесь не срабатывает из-за разницы в аппаратах восприятия участников, но взаимопонимание все равно достигается - благодаря доверию человека тому, что его поводырь может совершить следующее релевантное действие в рамках общей деятельности перемещения.

\section{Инфраструктурная инерция}

Если телесность представляет собой фундамент для интерсубъективности благодаря ее роли в поддержании общего курса действий, речь выступает основой для взаимопонимания в силу ее собственной организации. Во-первых, каждый следующий черед выражает интерпретацию предыдущего, и каждый черед может быть исправлен. Во-вторых, череда часто строятся на основе повторения (Sidnell 2014) или повторного использования с модификацией (Goodwin 2018), когда часть фразы повторяется следующим говорящим. В практиках исправления это служит цели указать на источник затруднения. Например, так называемом Wh-questions ${ }^{1}$ указывают на конкретный элемент предшествующего череда, который нуждается в исправлении, в отличие от общих вопросов вроде «Что?», которые чаще всего связаны с проблемой слышимости. Жестикуляция не имеет названных свойств, поскольку объект указательного жеста не содержится в нем самом. По словам Джека Сиднелла: «Что касается взаимодействия и интерсубъективности, язык меняет все» (Sidnell 2014: 391).

Будучи мощным охранительным механизмом взаимопонимания, речь может стать источником проблем в асимметричном взаимодействии. Если ЛсИ с нарушениями функции речи или слуха (афазия, дизартрия, частичная или полная потеря слуха) вынуждены ее использовать, они часто оказываются в уязвимом положении. Например, они не могут говорить достаточно быстро или разборчиво. Скот Барнс (Barnes 2014), исследовавший взаимодействие

\footnotetext{
${ }^{1}$ Вопросы, начинающиеся с вопросительного слова, типа «Когда», «Где», «Кто» и др.
} 
людей с афазией, отмечает, что исправление часто не происходит после фрагмента неразборчивой речи. Условно здоровые собеседники людей с афазией вместо исправления используют стратегии связывания разговора, обращаясь к предшествующим непроблемным чередам. Вероятнее всего, это не следствие отсутствия заинтересованности, а эффект используемой инфраструктуры взаимодействия. Поскольку разговор движим предпочтением развития, а исправление сложно в реализации, оно может быть опущено для сохранения связности разговора. В асимметричном взаимодействии эта структура предпочтения может, напротив, нарушать связность, поскольку она способствует систематическому игнорированию того, что релевантно для некоторых ЛсИ. ${ }^{1}$

Последние далеко не всегда могут или хотят производить исправление самостоятельно. Авторы исследования взаимодействия слабослышащих детей, использующих кохлеарные имплантаты, с нормально слышащими обнаружили, что они сами не инициировали исправление собеседников в случаях, когда источник затруднения был очевиден и мешал продвижению разговора (Church et al. 2017: 63). При этом они успешно делали это из-за проблем со слышимостью. Причиной этого, по мнению авторов, является высокая интеракционная «стоимость» исправления: с одной стороны, дети не чувствуют себя уверенно в разговоре и поэтому могут говорить неуклюже; с другой стороны, они боятся злоупотреблять исправлениями, поскольку и так часто их осуществляют из-за проблем со слухом. Таким образом, привычные для условно здоровых людей структуры взаимодействия могут стать источником непонимания в асимметричном взаимодействии.

Приведенные примеры иллюстрируют достижение взаимопонимания в отсутствии интерсубъективности, когда участники не могут полагаться на привычные охранительные механизмы речи. Даже если условно здоровые люди пытаются подстроиться под ЛсИ, у них не всегда получается. Это связано с тем, что практики, задействующие определенную инфраструктуру, подвержены ее инерции, т.е. продолжают осуществляться в фоновом режиме. Так, совершенно очевидно, что незрячий человек не увидит указательный жест, однако тот все равно производится (vom Lehn 2010).

\section{Заключение}

Точкой отсчета для исследований в области $E M C A$ являются компетентные члены общества одинаково владеющие навыками социального взаимодействия- умением встроиться в структуру очередности, привлечь к себе внимание или продемонстрировать (не)понимание. Асимметричное взаимодействие, в противоположность этому, характеризуется градиентом интерактивной компетентности, т.е. умением пользоваться доступными ресурсами. Нас интересовали условия взаимопонимания в таком взаимодействии.

\footnotetext{
${ }^{1}$ См. эмпирическую иллюстрацию в статье Е. Рудневой в этом выпуске.
} 
В $E M C A$ понимание, или интерсубъективность, концептуализируется как локальное достижение, обеспечиваемое фундаментальными структурами взаимодействия - системой очередности, последовательностей организации действий, предпочтения и исправления. Такая концептуализация не дает ответа на вопрос, что происходит, когда названные механизмы перестают быть прочной опорой. В этой работе мы предложили провести различение между взаимопониманием внутри ситуации и интерсубъективностью как приобретаемой способностью ориентироваться на другого. Это позволило: (а) выделить условия достижения интерсубъективности; (б) показать следствия отсутствия интерсубъективности или понимания в асимметричном взаимодействии. Во-первых, структуры взаимодействия в условиях симметрии выполняют охранительную функцию, тогда как в асимметричном взаимодействии они, наоборот, могут усложнять достижение взаимопонимания внутри ситуации. Во-вторых, компенсация тех или иных интерактивных ресурсов, например с помощью технологий, сама по себе не приводит к взаимопониманию. Необходимо участие в общем курсе действий, что связано с достижением интерсубъективности-доверия, что другой в состоянии совершить следующее релевантное действие в рамках последовательности. Интерсубъективность соотносится с сонастройкой взаимодействующих друг на друга; ее достижение, в сущности, означает, что взаимодействие становится более симметричным, даже когда интерактивные ресурсы участников сильно отличаются.

\section{Выражения признательности}

Статья подготовлена в рамках научно-исследовательской работы Центра социологических исследований РАНХиГС «Исследование динамики социальных связей, коллективных представлений и повседневных практик (2013-2021): долгосрочные эффекты» (2021).

Я выражаю благодарность Александре Курленковой за правки, которые позволили сделать этот текст лучше.

\section{Список источников}

Корбут А.М. (2015). Говорите по очереди: нетехническое введение в конверсационный анализ. Сочиологическое обозрение, 14 (1): 120-141.

Сакс Х., Щеглофф Э., Джефферсон Г. (2015) Простейшая систематика организации очередности в разговоре. Сочиологическое обозрение, 14 (1): 142-202.

Шюц А. (2004) Избранное: Мир, светящийся смыслом. М.: РОССПЭН.

Auer P., Hörmeyer I. (2017) Achieving Intersubjectivity in Augmentative and Alternative Communication (AAC). In: C. Meyer, J. Streeck, J.S. Jordan (eds.) Intercorporeality: Emerging Socialities in Interaction. Oxford: Oxford University Press:323-360.

Barnes S. (2014) Managing Intersubjectivity in Aphasia. Research on Language and Social Interaction, 47 (2): 130-150. 
Church A., Paatsch L., Toe D. (2017) Some Trouble with Repair: Conversations Between Children with Cochlear Implants and Hearing Peers. Discourse Studies, 19 (1):49-68.

Due B., Lange S. (2018a) Semiotic Resources for Navigation: A Video Ethnographic Study of Blind People's Uses of the White Cane and a Guide Dog for Navigating in Urban Areas. Semiotica, (222):287-312.

Due B., Lange S. (2018b) The Moses Effect: The Spatial Hierarchy and Joint Accomplishment of a Blind Person Navigating. Space and Culture, 21 (2): 129-144.

Garfinkel H. (1967) Studies in Ethnomethodology. Englewood Cliffs: Prentice-Hall.

Goffman E. (1963) Stigma. Notes on the Management of Spoiled Identity. Englewood Cliffs: Prentice-Hall.

Goode D. (1994) A World without Words: The Social Construction of Children Born Deaf and Blind. Philadelphia: Temple University Press.

Goodwin C. (1995) Co-Constructing Meaning in Conversations with an Aphasic Man. Research on Language and Social Interaction, 28 (3): 233-260.

Goodwin C. (2018) Co-operative Action. Cambridge: Cambridge University Press.

Heritage J. (1984) Garfinkel and Ethnomethodology. New York: Polity Press.

Kendrick K.H., Brown P., Dingemanse M., Floyd S., Gipper S., Hayano K., Levinson S.C. (2020) Sequence Organization: A Universal Infrastructure for Social Action. Journal of Pragmatics, (168): 119-138.

Luff P., Heath C., Kuzuoka H., Hindmarsh J., Yamazaki K., Oyama S. (2003) Fractured Ecologies: Creating Environments for Collaboration. Human-Computer Interaction, 18 (1-2): 51-84.

Meyer C., Streeck J., Jordan J. S. (eds.) (2017) Intercorporeality: Emerging Socialities in Interaction. Oxford: Oxford University Press.

Mondada L. (2016) Challenges of Multimodality: Language and the Body in Social Interaction. Journal of Sociolinguistics, 20 (3): 336-366.

Mondada L. (2019) Contemporary Issues in Conversation Analysis: Embodiment and Materiality, Multimodality and Multisensoriality in Social Interaction. Journal of Pragmatics, (145): 47-62.

Nevile M. (2015) The Embodied Turn in Research on Language and Social Interaction. Research on Language and Social Interaction, 48 (2): 121-151.

Schegloff E. A. (1992) Repair after Next Turn: The Last Structurally Provided Defense of Intersubjectivity in Conversation. American Journal of Sociology, 97 (5): 1295-1345.

Sidnell J. (2014) The Architecture of Intersubjectivity Revisited. In: N. J. Enfield, P. Kockelman, J. Sidnell (eds.) The Cambridge Handbook of Linguistic Anthropology. Cambridge: Cambridge University Press: $364-399$.

Valente D., Theurel A., Gentaz E. (2018) The Role of Visual Experience in the Production of Emotional Facial Expressions by Blind People: A Review. Psychonomic Bulletin \& Review, 25 (2): 483-497.

Wilkinson R. (2019) Atypical Interaction: Conversation Analysis and Communicative Impairments. Research on Language and Social Interaction, 52 (3):281-299.

Vom Lehn D. (2010) Discovering 'Experience-ables': Socially Including Visually Impaired People in Art Museums. Journal of Marketing Management, 26 (7-8): 749-769.

Vom Lehn D. (2018) Probing the Art/Science Binary: Notes on the Experimental Achievement of Shared Perception. In: P. Sormani, G. Carbone, P. Gisler (eds.) Practicing Art/Science. New York: Routledge: 101-124. 
Maria Erofeeva

\section{ACHIEVING INTERSUBJECTIVITY IN ASYMMETRIC INTERACTION}

The benchmark for ethnomethodology and conversation analysis (EMCA) is the competent member of society demonstrating, through their actions, and how the preceding actions of others were understood. The public accountability of mutual interpretations facilitates understanding, as incongruities immediately become noticeable. This is not always the case in asymmetric interaction, where the participants have different perceptual access to the world around them. To highlight this fact, the article discusses the conditions for achieving understanding in cases of atypical interactions. The first part of the paper examines the conversation-analytic conceptualization of mutual understanding, or intersubjectivity, as a local accomplishment facilitated by fundamental structures of interaction (e.g., turn-taking). This conceptualization does not explain what makes mutual understanding possible when participants have unequal access to these structures. The article argues that the effectiveness of interaction structures is itself based on the acquired capability to orient to the other's understanding. The author suggests calling this capability 'intersubjectivity,' distinguishing it from mutual understanding within the situation. In the second part of the paper, body and speech are considered as the fundamental foundations of intersubjectivity. It is demonstrated that replacing one interactive resource with another- using a speech synthesizer, for example- is successful only when the participants are bodily oriented towards each other. In asymmetric interaction, the conversational organization, which normally makes mutual understanding possible, can hinder it since routine interaction patterns continue to be used in the background. The author illustrates these arguments with examples from contemporary empirical EMCA research.

Keywords: ethnomethodology and conversion analysis, atypical interaction, multimodality, semiotic fields, intercorporeality

DOI: 10.17323/727-0634-2021-19-4-635-650

\section{References}

Auer P., Hörmeyer I. (2017) Achieving Intersubjectivity in Augmentative and Alternative Communication (AAC). In: C. Meyer, J. Streeck, J. S. Jordan (eds.) Intercorporeality: Emerging Socialities in Interaction. Oxford: Oxford University Press: 323-360.

Barnes S. (2014) Managing Intersubjectivity in Aphasia. Research on Language and Social Interaction, 47(2): 130-150.

Maria A. Erofeeva- Cand. Sci. (Sociol.), Researcher at the Center for Sociological Research, RANEPA; Senior Research Fellow at the International Center for Contemporary Sociological Theory, MSSES, Moscow, Russian Federation. Email: erofeeva-ma@universitas.ru 
Church A., Paatsch L., Toe D. (2017) Some Trouble with Repair: Conversations Between Children with Cochlear Implants and Hearing Peers. Discourse Studies, 19 (1): 49-68.

Due B., Lange S. (2018a) Semiotic Resources for Navigation: A Video Ethnographic Study of Blind People's Uses of the White Cane and a Guide Dog for Navigating in Urban Areas. Semiotica, (222): 287-312.

Due B., Lange S. (2018b) The Moses Effect: The Spatial Hierarchy and Joint Accomplishment of a Blind Person Navigating. Space and Culture, 21 (2): 129-144.

Garfinkel H. (1967) Studies in Ethnomethodology. Englewood Cliffs: Prentice-Hall.

Goffman E. (1963) Stigma. Notes on the Management of Spoiled Identity. Englewood Cliffs: Prentice-Hall.

Goode D. (1994) A World without Words: The Social Construction of Children Born Deaf and Blind. Philadelphia: Temple University Press.

Goodwin C. (1995) Co-Constructing Meaning in Conversations with an Aphasic Man. Research on Language and Social Interaction, 28 (3):233-260.

Goodwin C. (2018) Co-operative Action. Cambridge: Cambridge University Press.

Heritage J. (1984) Garfinkel and Ethnomethodology. New York: Polity Press.

Kendrick K.H., Brown P., Dingemanse M., Floyd S., Gipper S., Hayano K., Levinson S.C. (2020) Sequence Organization: A Universal Infrastructure for Social Action. Journal of Pragmatics, (168): 119-138.

Korbut A. M. (2015) Govorite po ocheredi: netekhnicheskoe vvedenie v konversatsionnyy analiz [Turn-talking: Non-technical Introduction to Conversation Analysis]. Sotsiologicheskoe obozrenie [Sociological Review], 14 (1): 120-141.

Luff P., Heath C., Kuzuoka H., Hindmarsh J., Yamazaki K., Oyama S. (2003) Fractured Ecologies: Creating Environments for Collaboration. Human-Computer Interaction, 18 (1-2): 51-84.

Meyer C., Streeck J., Jordan J. S. (eds.) (2017) Intercorporeality: Emerging Socialities in Interaction. Oxford: Oxford University Press.

Mondada L. (2016) Challenges of Multimodality: Language and the Body in Social Interaction. Journal of Sociolinguistics, 20 (3): 336-366.

Mondada L. (2019) Contemporary Issues in Conversation Analysis: Embodiment and Materiality, Multimodality and Multisensoriality in Social Interaction. Journal of Pragmatics, (145): 47-62.

Nevile M. (2015) The Embodied Turn in Research on Language and Social Interaction. Research on Language and Social Interaction, 48 (2): 121-151.

Sacks H., Schegloff E. A., Jefferson G. (2015) Prosteyshaya sistematika organizatsii ocherednosti v razgovore [A Simplest Systematics for the Organization of Turn-Taking for Conversation]. Sotsiologicheskoe Obozrenie [Russian Sociological Review], 14 (1): 142-202. 
Schegloff E. A. (1992) Repair after Next Turn: The Last Structurally Provided Defence of Intersubjectivity in Conversation. American Journal of Sociology, 97 (5): 1295-1345.

Schutz A. (2004) Izbrannoe: Mir, svetyashchiysya smyslom [Selected works: A World Glowing with Meaning]. Moscow: ROSSPEN.

Sidnell J. (2014) The Architecture of Intersubjectivity Revisited. In: N. J. Enfield, P. Kockelman, J. Sidnell (eds.) The Cambridge Handbook of Linguistic Anthropology. Cambridge: Cambridge University Press: 364-399.

Valente D., Theurel A., Gentaz E. (2018) The Role of Visual Experience in the Production of Emotional Facial Expressions by Blind People: A Review. Psychonomic Bulletin \& Review, 25 (2): 483-497.

Wilkinson R. (2019) Atypical Interaction: Conversation Analysis and Communicative Impairments. Research on Language and Social Interaction, 52 (3):281-299.

Vom Lehn D. (2010) Discovering 'Experience-ables': Socially Including Visually Impaired People in Art Museums. Journal of Marketing Management, 26 (7-8): 749-769.

Vom Lehn D. (2018) Probing the Art/Science Binary: Notes on the Experimental Achievement of Shared Perception. In: P. Sormani, G. Carbone, P. Gisler (eds.) Practicing Art/Science. New York: Routledge: 101-124. 